\title{
Zwei Kinderärzte verurteilt
}

\section{Tragisch: Hirnschaden durch Brechdurchfall}

Haben Säuglinge mehrere Tage Brechdurchfall, sollten alle Alarmglocken läuten: Zögern Ärzte in einem solchen Fall mit der Klinikeinweisung, und kommt es deswegen zu einer schweren hypertonen Dehydration, kann das leicht tödlich enden.

"In dubio pro statione“ lautet der Rat des Hamburger Rechtsanwalts Matthias Teichner bei Säuglingen mit Brechdurchfall, wenn dieser mehrere Tage anhält und keine Besserung erkennbar ist. Welche Folgen es für Patienten und Ärzte haben kann, wenn die Einweisung verzögert wird, macht Teichner am tragischen Fall eines neun Monate alten Kindes deutlich, bei dem gleich zwei niedergelassene Ärzte falsch reagiert hatten.

Das Kind wurde zunächst spät abends am 21. April 2003 mit Erbrechen und Durchfall in einer Klinik vorgestellt, berichtet Teichner in der Zeitschrift „pädiatrie hautnah“. Der verantwortliche Arzt diagnostizierte einen MagenDarm-Infekt und verordnete eine Elektrolytlösung sowie Perenterol. Mit der Mutter wurde vereinbart, dass sie das Kind bei einer Verschlechterung wieder vorstellt.

\section{Statt Untersuchung Folgerezept}

Am nächsten Tag suchte die Mutter mit ihrem Kind einen niedergelassenen Pädiater auf. Dieser erhielt den Arztbrief des Klinikkollegen. Darin war dokumentiert: „Seit gestern Erbrechen. Hält nichts bei sich." Der Pädiater injizierte dem Kind zwei Präparate gegen Übelkeit und Erbrechen. Am übernächsten Tag übergab eine Helferin des Arztes der
Mutter ein Wiederholungsrezept, ohne dass das Kind von ihm zuvor untersucht worden war, schreibt Teichner. Noch am selben Tag suchte die Mutter mit dem Kind eine niedergelassene Pädiaterin auf. Diese notierte: „Magen-Darm-Virus. Das Kind trinkt jetzt nicht. Versuch mit strenger Diät z. B. Tee. Heilnahrung mindestens 700 bis $1000 \mathrm{ml}$ bis abends, sonst Klinik."

\section{Hirnschaden durch Dehydration}

Am Morgen des 25. April, so der Rechtsanwalt, fanden zwei Telefonate zwischen der Mutter und der Kinderärztin statt. In der Karteikarte der Ärztin wurde notiert: „Klinik oder zumindest Wiedervorstellung Arzt." Weiter fand sich der Vermerk „Sofort Klinik oder Wiedervorstellung." Daraufhin ging die Mutter mit ihrem Kind in die Universitätsklinik. Die Ärzte dort diagnostizierten eine schwere hypertone Dehydration. Sämtliche Therapieversuche konnten aber nicht verhindern, dass das Kind eine Hirnschädigung erlitt. Der Fall kam vor das Landgericht, das zunächst nur der Klage gegenüber dem ersten Pädiater stattgab, in der Berufung wurde allerdings auch die Kinderärztin zu Schadensersatz verurteilt.

Dem Urteil des Oberlandesgerichts in Köln zufolge hätte bereits der als erstes konsultierte Pädiater das Kind sofort am 22. April in ein Krankenhaus einweisen müssen. Der Sachverständige des Gerichts gab an, „Mit dem zeitgleichen Auftreten von protrahiertem Durchfall und Erbrechen sei bei dem Kind der Zeitpunkt gekommen, in dem der Zustand durch eine rein orale Flüssigkeitszufuhr nicht mehr zu bewältigen war", schreibt Teichner. Zudem sei der erste Pädiater nach Auffassung des Sachverständigen dazu verpflichtet gewesen, in seiner Praxis zu kontrollieren, wie viel das Kind tatsächlich getrunken hatte.

Die Versäumnisse des ersten niedergelassenen Pädiaters waren nach Ansicht des Gerichts auch die Ursache für den Hirnschaden des Kindes. „Ein grober Behandlungsfehler müsse auch deshalb angenommen werden, weil der Beklagte seine Praxis mangelhaft organisiert hatte. Das Ausfüllen und das Aushändigen eines Folgerezepts darf nur dann an Mitarbeiter delegiert werden, wenn kein Erbrechen und/oder Durchfall beim erkrankten Kind mehr auftritt. Vorliegend wurde es versäumt, dass das Kind noch einmal vom Arzt gründlich und persönlich untersucht wurde", beschreibt Teichner die Urteilsbegründung.

\section{Auch nach drei Tagen keine Einweisung}

Allerdings wäre auch die später aufgesuchte Pädiaterin nach Ansicht des OLG dazu verpflichtet gewesen, das Kind sofort in eine Klinik einzuweisen. „Die Untersuchung des Kindes durch die Beklagte erfolgte am 24. April 2003, als Erbrechen und Durchfall bereits drei Tage anhielten. Eine Therapie mittels einer oralen Rehydrationslösung kam an diesem Tag nicht mehr in Betracht. Die Ärztin hätte der Mutter erklären müssen, dass für das Kind die Gefahr einer schwerwiegenden, andauernden Gesundheitsschädigung und sogar des Todes bestand. Mithin wurde von der Ärztin die sogenannte Sicherungsaufklärung verletzt", zitiert der Rechtsanwalt die Urteilsbegründung.

(Thomas Müller)

pädiatrie hautnah, 2011; 23:488-91 